\title{
Da lógica do gasto à do custo: financiamento do ensino médio integral
}

\author{
From the spent logic to the cost logic: \\ the financing high school full-time

\section{De la lógica del gasto a la lógica del costo: \\ financiación de la escuela secundaria integral}

\author{
ALINY C. S. ALVES* \\ Univesidade Federal do Pará, Belém- PA, Brasil. \\ FABRÍCIO A. F. CARVALHO** \\ Univesidade Federal do Pará, Belém- PA, Brasil.
}

\begin{abstract}
RESUMO: O artigo analisa o financiamento da educação no Brasil com o intuito de revelar a lógica que orientou a política de fundos (Fundef e Fundeb), suas dificuldades e limites para o financiamento do ensino médio em tempo integral de qualidade. O estudo bibliográfico sobre financiamento da educação e a análise das leis n 9.394/96 (LDB), $\mathrm{n}^{\circ}$ 9.424/96 (Fundef), n¹1.494 (Fundeb) revelaram que a lógica do gasto, com a redistribuição de recursos pelo número de matrículas nos níveis de ensino e modalidades na educação básica, desde a implantação da política de fundos, não tem dado conta de ampliar o acesso ao ensino médio em tempo integral nos patamares estabelecidos pelo PNE (Lei n. 13.005/2014) e tampouco o acesso com qualidade. Como alternativa, destaca-se a lógica do custo (CAQI), que prevê os insumos necessários para um ensino médio em tempo integral de qualidade.

Palavras-chave: Financiamento. Ensino médio. Tempo integral.
\end{abstract}

* É graduada em Pedagogia pela Universidade Federal do Pará e Mestra em Currículo e Gestão da Escola Básica pela mesma instituição. Atua como professora das séries inicias e da Educação de Jovens e Adultos na rede Municipal de Belém. E-mail: <aliny.alves@gmail.com>.

* Mestre em Educação pela Universidade Federal do Pará e Doutor em Educação pela Universidade de São Paulo. Atualmente é Professor Adjunto do Núcleo de Estudos Transdisciplinares em Educação Básica da Universidade Federal do Pará (NEB/UFPA). E-mail:<fafc33@gmail.com>. 
ABSTRACT: this article analyzes the financing of education in Brazil with the purpose of revealing the logic that guided the policy of funds (Fundef and Fundeb), yours difficulties and limits to the funding of high school full-time quality. Through a bibliographic review on the financing of education and documentary study in the analysis the laws of LDB nº 9.394 / 96, Fundef no 9.424 / 96 and Fundeb no 11.494, etc. The study revealed that the logic of spending, with the redistribution of resources by the number of enrollments in levels of education and modalities in basic education since the implementation of the policy of funds, has not taken into account to increase access to high school full-time in the levels established by the PNE (Law n⿳o 13.005 / 2014) and so little to access with quality. As an alternative, the cost logic (CAQI), which provides the necessary inputs for a full-time high school quality education, is highlighted in the study.

Keyword: Financing. High scool. Full-time.

RESUMEN: El artículo analiza el financiamiento de la educación en Brasil para revelar la lógica que guio la política de los fondos (Fundef y Fundeb), sus dificultades y límites a la calidad del financiamiento de la escuela secundaria integral y de calidad. El estudio bibliográfico sobre financiación de la educación y el análisis de las leyes nº .9.394/96 (LDB), nº. 9.424/96 (Fundef), nº 11.494 (Fundeb) revelaron que la lógica del gasto, con la redistribución de recursos según el número de inscripciones en los niveles de enseñanza y modalidades en educación básica, desde la implementación de la política del fondo, no ha sido capaz de ampliar el acceso a la escuela secundaria a tiempo integral a los niveles establecidos por el PNE (Ley no‥13.005/2014) ni tampoco lo acceso con calidad. Alternativamente, destacamos la lógica de CAQI, que proporciona los insumos necesarios para una escuela secundaria integral y de calidad.

Palabras clave: Financiamiento. Escuela secundaria Enseñanza a tiempo completo. 


\section{Introdução}

temática do financiamento da educação brasileira tem sido alvo de muitos
questionamentos no século XXI, e foi objeto de estudos no final do século XX,
pois o processo de redemocratização do Estado brasileiro ao final da década de 1980 e o movimento econômico de adoção de medidas de cunho neoliberal no País, a partir da década de 1990, colocaram em cheque o desafio de universalizar o ensino, garantir a qualidade e o pleno desenvolvimento humano, com menos recursos e maior controle de resultados, seguindo a lógica neoliberal.

Neste cenário, a necessidade de estudos na área do financiamento da educação se justifica como forma de "conscientização e politização fundamentais" (MONLEVADE, 1997, p.7) para quem se preocupa com a educação como um direito e que deve ser ofertado com qualidade para a população brasileira. E ainda, como lembra Ramos (2003):

O financiamento da educação é parte integrante das políticas educacionais e consiste em poderoso e indispensável elemento para efetivá-las' sendo 'instrumento igualmente poderoso para que se identifique a face oculta dessas políticas, desvendando sua verdadeira natureza (RAMOS, 2003, p. 25).

O presente estudo aborda o financiamento educacional relacionando-o à garantia do direito à educação enquanto um direito público subjetivo, que deve ser garantido com qualidade social e que pode ser exigido por qualquer cidadão brasileiro que não tenha acesso a ele. Parte-se dos artigos da Constituição Federal de 1988 e da LDB 9394/96, que tratam da vinculação de recursos do Orçamento Público para a Educação, com um mínimo de recurso financeiro público pelo regime de colaboração entre os entes federados, segundo suas prioridades de gastos com o serviço educacional para atendimento de crianças, adolescentes, jovens e adultos.

Para fundamentação do estudo, utilizou-se autores, como Madza e Bassi (2009), Carvalho (2006; 2012), Davies (2006), Menezes (2015), Monlevade (1997), Rossinholi (2010), Saviani (2008) e Vieira e Vidal (2009), os quais tratam do financiamento da educação brasileira, seus aspectos históricos e atuais quanto à vinculação de recursos, a política de fundos (Fundef e Fundeb) e a necessidade de maiores recursos financeiros para a educação, bem como buscou-se fazer uma diferenciação sobre os conceitos de gasto e custo, os quais perpassarão toda a análise das características do financiamento educacional aqui estudado.

Definiu-se a etapa do ensino médio em tempo integral como foco do estudo a fim de analisar, pelo estudo documental e bibliográfico, as características utilizadas para o financiamento e a oferta de ensino com qualidade. Por fim, faz-se referência à lógica do custo, apresentada pelos estudos do CAQi (Custo Aluno-Qualidade Inicial) e CAQ (Custo Aluno-Qualidade), sintetizados por Carreira e Rezende Pinto (2007) e defendidos pela sociedade civil organizada por meio da Campanha Nacional pelo Direito à Educação. 


\section{O financiamento da educação por meio do FUNDEF E FUNDEB}

Na história do financiamento da educação no Brasil, até o texto da Constituição Federal de 1988 (CF-1988), ocorreram alguns avanços e retrocessos para a manutenção da educação pública brasileira que refletem, segundo Rossinholi (2010, p.15), "momentos de continuidade, rupturas e tendências sobre a concepção do papel do Estado no que se refere à Educação". Ressalta-se que a história do financiamento educacional brasileiro está contemplada em estudos como o de Monlevade $(1997)^{1}$, o qual explicita a forma de vinculação e não vinculação de recursos financeiros por parte do Governo brasileiro na área da educação, desde a época da colonização até a CF-1988.

Em seu art. 212, a CF-1988 apresenta a forma de vinculação para o financiamento da educação nacional de acordo com as responsabilidades de cada ente federado:

A União aplicará, anualmente, nunca menos de dezoito, e os Estados, o Distrito Federal e os Municípios vinte e cinco por cento, no mínimo, da receita resultante de impostos, compreendida a proveniente de transferências, na manutenção e desenvolvimento do ensino (BRASIL, 1988).

Esta tem sido a prática de vinculação dos recursos financeiros dos entes federados na educação pública no Brasil, até o ano de 2016, seguindo uma lógica de descentralização e/ou redistribuição de recursos. Ter garantida a vinculação constitucional de recursos para a educação nacional já é um avanço do ponto de vista do financiamento, porém, não significa que o direito à Educação esteja plenamente garantido.

As políticas de financiamento educacionais no Brasil sempre estiveram ligadas diretamente às exigências do mercado produtivo, e aos interesses de desenvolvimento econômico no Brasil. Conforme afirma Ramos (2003):

\footnotetext{
No Brasil, durante toda a curta história da educação e, especialmente, após o início do século 20, tem se manifestado o apelo à ampliação e à manutenção do ensino como forma de viabilizar a "preparação dos recursos humanos", indispensáveis à modernização e ao crescimento econômico. Será a partir daí que os poderes públicos vão mostrar um certo grau de preocupação com a educação e, particularmente, com seu financiamento (p. 41).
}

É nesse contexto que, na década de 1990, o Brasil, totalmente envolvido com a política neoliberal instalada internacionalmente, envolve-se mais diretamente com as exigências impostas pelas agências e organismos comandados pelo FMI (Fundo Monetário Internacional) e pelo Bird (Banco Mundial), principais financiadores do "desenvolvimento" econômico dos países subdesenvolvidos, incluindo o Brasil.

Medidas como a descentralização de recursos e sua redistribuição, não necessariamente aumento do volume de recursos financeiros, a implantação de medidas de controle por meio das políticas de avaliação externa, a busca de "fontes alternativas de 
financiamento da educação" (RAMOS, 2003, p. 130) passaram a ser práticas dominantes na política educacional brasileira.

É neste cenário que o Estado inicia uma série de mudanças significativas no financiamento da educação brasileira, a partir da CF-1988, da LDB-1996 e das políticas de Fundo estabelecidas com o Fundef e, posteriormente, com o Fundeb, sendo estas últimas consideradas a "grande mudança sistemática de financiamento da educação" (RAMOS, 2003, p. 273)

Com a vinculação de impostos e os percentuais mínimos de recursos financeiros definidos na CF-1988 para a educação, no ano de 1996, foi aprovada a Emenda Constitucional nº 14, e em 12 de setembro de 1996 é criado o Fundo de Manutenção e Desenvolvimento do Ensino Fundamental e de Valorização do Magistério (Fundef), regulamentado posteriormente pela Lei $\mathrm{n}^{0}$ 9.424/96. Esse fundo gerou a subvinculação de recursos mínimos para o ensino fundamental, seguindo as orientações da economia de mercado e dos organismos internacionais (Banco Mundial, Organização das Nações Unidas, Organização das Nações Unidas para a Educação, entre outros), com a priorização de um determinado nível de ensino e prazo de vigência até o ano de 2006 (RAMOS, 2003).

O Fundef compreendia um fundo de natureza contábil que reunia fundos dos três entes federados e, de forma redistributiva, seria enviado aos estados para garantir a manutenção do ensino de acordo com o número de matrículas no ensino fundamental regular (MADZA; BASSI, 2009 e CARVALHO, 2012). Foi considerado por vários autores como política focal, que, ao priorizar uma etapa da educação básica, prejudicou a educação infantil e o ensino médio, bem como as demais modalidades de oferta, incluindo a educação de jovens e adultos (EJA), que tiveram recursos diminuídos e seus índices ainda mais prejudicados (MADZA; BASSI, 2009 e SAVIANI, 2008)

Em dez anos de vigência, pesquisas indicam algumas contribuições, mesmo que limitadas, do Fundef para a educação nacional, como afirma Guimarães (2010):

É avaliação corrente que a implantação do FUNDEF, a partir de 1998, contribuiu para a ampliação do atendimento no âmbito do ensino fundamental, deixando, porém, fora do processo de inclusão as crianças em idade escolarizável na educação infantil e a demanda crescente de jovens pelo ensino médio (p.3).

Segundo Gouveia e Souza (2015), a política do Fundef continuou a perspectiva de distribuição de recursos disponíveis, neste artigo chamados de lógica do "gasto", pois, ao invés de aumentar os recursos para a educação, o ministro da Educação da época, Paulo Renato Souza, afirmava que faltava melhor gestão dos recursos disponíveis; mas não houve relação entre o mínimo a ser gasto e as reais necessidades da educação:

O mecanismo previsto no Fundef era de composição do fundo considerando os recursos disponíveis via vinculação constitucional de cada Estado federado e seus municípios e a sua redistribuição com base em um gasto por aluno ao ano mínimo definido nacionalmente. Certamente, se esse gasto mínimo por aluno nacional 
expressasse uma relação direta entre o bem produzido - a escola em pleno funcionamento - e os recursos necessários à garantia das condições de qualidade da oferta, poderíamos chegar à ideia de custo (GOUVEIA; SOUZA, 2015, p.50).

Devido à diferença de arrecadação dos municípios e estados brasileiros, em determinadas regiões o valor correspondente aos $25 \%$ mínimos para investimento em educação eram muito poucos para ofertá-la com qualidade. A política de fundos não considerou esse problema; ao invés de implementar uma revisão da política tributária e prover aumento de recursos para a educação, apenas redistribuiu entre os municípios o quantitativo arrecadado em cada estado, não resolvendo as diferenças entre as regiões brasileiras, e ainda aumentando as disparidades entre os níveis de ensino, dentro dos próprios sistemas municipais. Gouveia e Souza (2015, p. 51) consideram que "o Fundef foi desenhado sob uma perspectiva de contenção de despesas da União e racionalização de gastos nos entes federados".

Diante de tais prejuízos, Madza e Bassi (2009, p. 101) indicam que a experiência com o Fundef ensinou que "só é possível pensar em atendimento ao direito à educação de forma sistêmica. É preciso investir na educação básica como um todo: esforços em um setor isolado dos demais acabam não beneficiando nem mesmo a esse setor".

Destaca-se que na política de fundos estabelecida pelo Fundef não houve espaço para a etapa do ensino médio, devido à subvinculação de recursos para o ensino fundamental. Desta forma, havia necessidade de ampliação dos recursos para o atendimento da juventude brasileira, além das demais etapas de ensino, e a sociedade organizada começou a sentir tal necessidade.

Com a pressão social diante de tantos problemas causados pelo Fundef, e com a perspectiva do novo Governo a partir de 2002, cria-se o Fundo de Manutenção e Desenvolvimento da Educação Básica e de Valorização dos Profissionais da Educação (Fundeb), pela Emenda Constitucional n ${ }^{\circ}$ 53, de 19 de dezembro de 2006, posteriormente regulamentado pela Lei 11.494, de 20 de junho de 2007, com prazo de vigência até 2020.

O Fundeb amplia o quantitativo de recursos, mas aumenta também a abrangência de atendimento, passando a atender toda a educação básica, incluindo educação infantil e o ensino médio. Para alguns estudiosos sobre financiamento, o Fundeb seria uma esperança de democratização da educação pública, um passo avante por considerar importantes todas as etapas e modalidades da educação básica, porém, retrai alguns passos, pois seus recursos não aumentaram na mesma proporção do volume de matrículas (MADZA; BASSI, 2009 e SAVIANI, 2008).

Tanto no Fundef quanto no Fundeb, o valor aluno-ano calculado para os diferentes níveis de ensino tem como referência o valor para o ensino fundamental, e assume valores de ponderações a mais ou a menos para os demais níveis de ensino em suas diferentes modalidades de oferta. De acordo com Gouveia e Souza (2015): 
A Lei no 11.494 definiu, no artigo 10, que a redistribuição dos recursos deve levar em conta as "diferenças entre etapas, modalidades e tipos de estabelecimento de ensino da educação básica" (Brasil, Lei nº 11.494, 2007), o que resultou na descrição de 27 variações de tipo de gasto por aluno (p.57).

Destaca-se que o Fundeb passou a considerar o ensino em tempo integral em todos os níveis, diferenciando tal valor na ponderação de 1,30, o que já se pode considerar um avanço, porém, sem o estabelecimento das características necessárias para se chegar a tal valor. Como se pode observar na figura 1 têm-se os valores correspondentes ao cálculo das ponderações que regem o valor aluno-ano a partir do Fundeb:

Figura 1 - Fatores de Ponderação Fundeb (2007 a 2015)

\begin{tabular}{|c|c|c|c|c|c|c|c|c|c|}
\hline \multirow{2}{*}{$\begin{array}{l}\text { Etapas e Mo- } \\
\text { dalidades e } \\
\text { seguimentos }\end{array}$} & $\begin{array}{c}\text { Resolução } \\
\mathrm{n}^{0} 1 \mathrm{de} \\
15 / 02 / 2007\end{array}$ & $\begin{array}{c}\text { Portaria } \\
\mathrm{n}^{\circ} 41 \text { de } \\
27 / 12 / 2007\end{array}$ & $\begin{array}{c}\text { Portaria } \\
\text { no }^{\circ} 932 \text { de } \\
30 / 07 / 2008\end{array}$ & $\begin{array}{c}\text { Portaria } \\
\text { n }^{\circ} 777 \text { de } \\
10 / 08 / 2009\end{array}$ & $\begin{array}{c}\text { Portaria } \\
\mathrm{n}^{0} 873 \mathrm{de} \\
01 / 07 / 2010\end{array}$ & $\begin{array}{c}\text { Portaria } \\
\mathrm{n}^{0} 1322 \text { de } \\
21 / 09 / 2011\end{array}$ & $\begin{array}{c}\text { Resolução } \\
\text { nno }^{0} \mathrm{de} \\
25 / 07 / 2012\end{array}$ & $\begin{array}{c}\text { Resolução } \\
\mathrm{n}^{0} 1 \text { de } \\
31 / 12 / 2013\end{array}$ & $\begin{array}{c}\text { Resolução } \\
\mathrm{n}^{\circ} 1 \text { de } \\
24 / 07 / 2014\end{array}$ \\
\hline & 2007 & 2008 & 2009 & 2010 & 2011 & 2012 & 2013 & 2014 & 2015 \\
\hline Creche & 0,80 & - & - & - & - & - & - & - & - \\
\hline $\begin{array}{l}\text { Creche } \\
\text { pública de } \\
\text { tempo parcial }\end{array}$ & - & 0,80 & 0,80 & 0,80 & 0,80 & 0,80 & 0,80 & 1,0 & 1,0 \\
\hline $\begin{array}{l}\text { Creche } \\
\text { conveniada } \\
\text { com tempo } \\
\text { parcial }\end{array}$ & - & 0,80 & 0,80 & 0,80 & 0,80 & 0,80 & 0,80 & 0,80 & 0,80 \\
\hline $\begin{array}{l}\text { Creche } \\
\text { pública de } \\
\text { tempo integral }\end{array}$ & - & 1,10 & 1,10 & 1,10 & 1,20 & 1,30 & 1,30 & 1,30 & 1,30 \\
\hline $\begin{array}{l}\text { Creche } \\
\text { conveniada de } \\
\text { tempo integral }\end{array}$ & - & 0,85 & 0,95 & 1,10 & 1,10 & 1,10 & 1,10 & 1,10 & 1,10 \\
\hline Pré-escola & 0,90 & - & - & - & - & - & - & - & - \\
\hline $\begin{array}{l}\text { Pré-escola } \\
\text { parcial }\end{array}$ & - & 0,90 & 1,00 & 1,0 & 1,0 & 1,0 & 1,0 & 1,0 & 1,0 \\
\hline $\begin{array}{l}\text { Pré-escola } \\
\text { integral }\end{array}$ & - & 1.15 & 1.20 & 1.25 & 1.30 & 1.30 & 1.30 & 1.30 & 1.30 \\
\hline $\begin{array}{l}\text { Anos iniciais } \\
\text { ensino } \\
\text { fundamental } \\
\text { urbano }\end{array}$ & 1,0 & 1,0 & 1,0 & 1,0 & 1,0 & 1,0 & 1,0 & 1,0 & 1,0 \\
\hline $\begin{array}{l}\text { Anos iniciais } \\
\text { ensino } \\
\text { fundamental } \\
\text { rural }\end{array}$ & 1,05 & 1,05 & 1,05 & 1,15 & 1,15 & 1,15 & 1,15 & 1,15 & - \\
\hline
\end{tabular}




\begin{tabular}{|c|c|c|c|c|c|c|c|c|c|}
\hline \multirow[t]{2}{*}{$\begin{array}{l}\text { Etapas e Mo- } \\
\text { dalidades e } \\
\text { seguimentos }\end{array}$} & $\begin{array}{c}\text { Resolução } \\
\mathrm{n}^{0} 1 \mathrm{de} \\
15 / 02 / 2007\end{array}$ & $\begin{array}{c}\text { Portaria } \\
\mathrm{n}^{\circ} 41 \text { de } \\
27 / 12 / 2007\end{array}$ & $\begin{array}{c}\text { Portaria } \\
\mathrm{n}^{0} 932 \text { de } \\
30 / 07 / 2008\end{array}$ & $\begin{array}{c}\text { Portaria } \\
\mathrm{n}^{\circ} 777 \text { de } \\
10 / 08 / 2009\end{array}$ & $\begin{array}{c}\text { Portaria } \\
\mathrm{n}^{\circ} 873 \mathrm{de} \\
01 / 07 / 2010\end{array}$ & $\begin{array}{c}\text { Portaria } \\
\mathrm{n}^{0} 1322 \text { de } \\
21 / 09 / 2011\end{array}$ & $\begin{array}{c}\text { Resolução } \\
\mathrm{n}^{\circ} 8 \mathrm{de} \\
25 / 07 / 2012\end{array}$ & $\begin{array}{c}\text { Resolução } \\
\mathrm{n}^{0} 1 \mathrm{de} \\
31 / 12 / 2013\end{array}$ & $\begin{array}{c}\text { Resolução } \\
n^{0} 1 \text { de } \\
24 / 07 / 2014\end{array}$ \\
\hline & 2007 & 2008 & 2009 & 2010 & 2011 & 2012 & 2013 & 2014 & 2015 \\
\hline $\begin{array}{l}\text { Anos iniciais } \\
\text { ensino } \\
\text { fundamental } \\
\text { no campo }\end{array}$ & - & - & - & - & - & - & - & 1,15 & 1,15 \\
\hline $\begin{array}{l}\text { Anos finais- } \\
\text { Ensino } \\
\text { fundamental } \\
\text { urbano }\end{array}$ & 1,10 & 1,10 & 1,10 & 1,10 & 1,10 & 1,10 & 1,10 & 1,10 & 1,10 \\
\hline $\begin{array}{l}\text { Anos Finais- } \\
\text { Ensino } \\
\text { Fundamental } \\
\text { Rural }\end{array}$ & 1,15 & 1,15 & 1,15 & 1,20 & 1,20 & 1,20 & 1,20 & 1,20 & - \\
\hline $\begin{array}{l}\text { Anos Finais- } \\
\text { Ensino } \\
\text { Fundamental } \\
\text { campo }\end{array}$ & - & - & - & - & - & - & - & 1,20 & 1,20 \\
\hline $\begin{array}{l}\text { Ensino } \\
\text { Fundamental } \\
\text { integral }\end{array}$ & 1,25 & 1,25 & 1,25 & 1,25 & 1,25 & 1,30 & 1,30 & 1,30 & 1,30 \\
\hline $\begin{array}{l}\text { Ensino Médio } \\
\text { Urbano }\end{array}$ & 1,20 & 1,20 & 1,20 & 1,20 & 1,20 & 1,20 & 1,20 & 1,25 & 1,25 \\
\hline $\begin{array}{l}\text { Ensino Médio } \\
\text { no campo }\end{array}$ & 1,25 & 1,25 & 1,25 & 1,25 & 1,25 & 1,30 & 1,30 & 1,30 & 1,30 \\
\hline $\begin{array}{l}\text { Ensino Médio } \\
\text { Integral }\end{array}$ & 1,30 & 1,30 & 1,30 & 1,30 & 1,30 & 1,30 & 1,30 & 1,30 & 1,30 \\
\hline $\begin{array}{l}\text { Ensino Médio } \\
\text { Integrado } \\
\text { à Educação } \\
\text { Profissional }\end{array}$ & 1,30 & 1,30 & 1,30 & 1,30 & 1,30 & 1,30 & 1,30 & 1,30 & 1,30 \\
\hline $\begin{array}{l}\text { Educação } \\
\text { Especial }\end{array}$ & 1,20 & 1,20 & 1,20 & 1,20 & 1,20 & 1,20 & 1,20 & 1,20 & 1,20 \\
\hline $\begin{array}{l}\text { Educação } \\
\text { Indígenae } \\
\text { Quilombola }\end{array}$ & 1,20 & 1,20 & 1,20 & 1,20 & 1,20 & 1,20 & 1,20 & 1,20 & 1,20 \\
\hline $\begin{array}{l}\text { Educação } \\
\text { de Jovense } \\
\text { Adultos com } \\
\text { avaliação no } \\
\text { processo }\end{array}$ & 0,70 & 0,70 & 0,80 & 0,80 & 0,80 & 0,80 & 0,80 & 0,80 & 0,80 \\
\hline
\end{tabular}




\begin{tabular}{|c|c|c|c|c|c|c|c|c|c|}
\hline \multirow[t]{2}{*}{$\begin{array}{l}\text { Etapas e Mo- } \\
\text { dalidades e } \\
\text { seguimentos }\end{array}$} & $\begin{array}{c}\text { Resolução } \\
\text { nº } 1 \text { de } \\
15 / 02 / 2007\end{array}$ & $\begin{array}{c}\text { Portaria } \\
\mathrm{n}^{\circ} 41 \mathrm{de} \\
27 / 12 / 2007\end{array}$ & $\begin{array}{c}\text { Portaria } \\
n^{0} 932 \text { de } \\
30 / 07 / 2008\end{array}$ & $\begin{array}{c}\text { Portaria } \\
n^{0} 777 \text { de } \\
10 / 08 / 2009\end{array}$ & $\begin{array}{c}\text { Portaria } \\
\mathrm{n}^{0} 873 \text { de } \\
01 / 07 / 2010\end{array}$ & $\begin{array}{c}\text { Portaria } \\
\mathrm{n}^{0} 1322 \text { de } \\
21 / 09 / 2011\end{array}$ & $\begin{array}{c}\text { Resolução } \\
\mathrm{n}^{0} 8 \text { de } \\
25 / 07 / 2012\end{array}$ & $\begin{array}{c}\text { Resolução } \\
\text { nº } 1 \text { de } \\
\text { 31/12/2013 }\end{array}$ & $\begin{array}{c}\text { Resolução } \\
\mathrm{n}^{0} 1 \mathrm{de} \\
24 / 07 / 2014\end{array}$ \\
\hline & 2007 & 2008 & 2009 & 2010 & 2011 & 2012 & 2013 & 2014 & 2015 \\
\hline $\begin{array}{l}\text { Educação } \\
\text { de Jovens } \\
\text { e Adultos } \\
\text { integrada } \\
\text { à educação } \\
\text { profissional de } \\
\text { nível médio } \\
\text { com avaliação } \\
\text { no processo }\end{array}$ & 0,70 & 0,70 & 1,0 & 1,0 & 1,20 & 1,20 & 1,20 & 1,20 & 1,20 \\
\hline
\end{tabular}

Fonte: Confederação Nacional dos Municípios. (CNM)

Mesmo na vigência do Fundef, os valores de ponderação já existiam para diferenciar o cálculo do repasse de recursos por aluno matriculado nas séries do ensino fundamental, anos iniciais e finais e suas modalidades. Porém, é no Fundeb que as ponderações assumem melhor diferenciação e as modalidades em tempo integral recebem um percentual a mais por estudante matriculado, inicialmente, $25 \%$ a mais e chegam a $30 \%$ a mais no ano de 2015.

Voltando à análise de custo, Gouveia e Souza (2015, p. 57) consideram que a existência das diferenças entre as formas de organização da escola "se aproxima da definição de custo aluno no contexto do Fundeb na medida em que sugere a necessidade de insumos diferentes para diferentes organizações de atendimento escolar". Entretanto, há um limite nessa diferenciação, pois, mesmo considerando as diferenças de insumos em cada modalidade e diferenciando as ponderações, a variação fica entre 0,70 (setenta centésimos) e 1,30 (um inteiro e trinta centésimos), independentemente de qual seja o nível ou modalidade de ensino, de acordo com o Art. 11 da Lein. 11.494/2007, que regulamenta o Fundeb.

De forma geral, a política de fundos não representou significativamente o aumento de recursos para educação pública brasileira. Saviani (2008) anuncia que a LDB apenas reforçou a indicação da criação da política de fundos que já estava em trâmite no Congresso Nacional, mais tarde aprovada pela EC nํ14, em 1997, e, ainda, ao não criar novas fontes de recursos para a educação, a política de fundos apenas redistribuiu os recursos já vinculados, diminuindo a participação da União e ampliando a participação dos estados e municípios com a efetivação do Fundef.

\section{Ensino médio em tempo integral no contexto dos fundos para a educação}

Como já afirmado, durante a vigência do Fundef, os recursos foram priorizados para a etapa do ensino fundamental e sua ampliação de atendimento e valorização dos 
professores causou até mesmo diferenciação no pagamento em relação aos demais profissionais que atuavam na educação infantil e no ensino médio.

O ensino médio só entra no campo de prioridade de financiamento a partir da criação do Fundeb, quando passa a ser considerado uma das etapas prioritárias e o seu atendimento passa a ser objeto de ampliação, sendo ainda consideradas as diferenciações para sua oferta - ensino médio regular urbano, ensino médio rural, ensino médio em tempo integral e ensino médio integrado à educação profissional - para a distribuição dos recursos.

No entanto, tal diferenciação foi somente numérica, pois se definiu um percentual de diferenciação, sem descrever ou esclarecer as reais necessidades de recursos para atendimento com qualidade da etapa do ensino médio em suas diferentes formas de oferta. Iguala-se na lógica vigente o ensino médio rural em tempo integral e integrado à educação profissional quanto ao valor aluno-ano, porém não se estabelecem os insumos necessários à oferta de cada modalidade em suas especificidades.

Os estudos realizados por Carreira e Pinto (2007) revelaram algumas preocupações ainda pertinentes em relação ao ensino médio, última etapa da educação básica. Apresentam-se aqui três destas preocupações inicias baseadas nas informações colhidas entre 2000 e 2001:

- embora a permanência tenha melhorado bastante, tanto no ensino fundamental (no qual ela já é superior aos oito anos obrigatórios) quanto no ensino médio, as taxas previstas de conclusão ainda são muito baixas e, no caso do ensino médio, devem piorar à medida que houver melhora no acesso;

- é preocupante o fato de metade dos alunos do ensino médio estudar no período noturno, geralmente em prédios que atendem o ensino fundamental no período diurno, o que mostra que esse nível de ensino funciona como um apêndice do ensino obrigatório, sem possuir uma identidade própria. À noite, alunos e professores estão cansados, o que compromete a qualidade do ensino e o rendimento dos alunos;

- quanto aos recursos de infraestrutura e equipamentos, a situação é crítica em todos os níveis da educação básica. [...] Nos ensinos fundamental e médio, a carência de bibliotecas, laboratórios de ciências e de informática. [...] A existência de pontos de internet é insignificante no ensino fundamental e muito abaixo do desejável nas escolas de ensino médio (2007, p. 38).

Mais uma vez observa-se que a situação ainda não sofreu tantas mudanças no que diz respeito ao que mais preocupava a sociedade civil organizada no momento do estudo, em 2007. Os desafios para o ensino médio brasileiro ainda são muitos, quanto aos vários tipos ofertados. O mais preocupante é o ensino médio noturno e as modalidades de EJA médio, pois, garantir a qualidade quando alunos e professores estão no fim do dia é um imenso desafio e a tendência na EJA é reduzir ao máximo o currículo, para ensinar somente o essencial e, ainda assim, o desempenho dos alunos não chega a ser satisfatório. 


\section{A lógica do CAQi para o financiamento do ensino médio de tempo integral}

Segundo Madza e Bassi (2009), a diferença de custo e gasto se dá basicamente porque, no gasto-aluno, o foco são as verbas existentes e no Custo Aluno-Qualidade o foco está nas verbas necessárias para que o aluno receba a educação de qualidade que merece - seu direito.

Logo, na perspectiva do gasto, a análise é do quanto se tem das verbas disponíveis para distribuir por aluno matriculado. Tal perspectiva é mais comumente utilizada durante toda a história do financiamento educacional brasileiro; embora a legislação garanta um padrão mínimo de qualidade, o financiamento não é pautado nesta garantia do direito à educação com qualidade e, sim, em um valor mínimo dos recursos financeiros arrecadados e no menor valor a ser gasto com educação.

Pensar na perspectiva do Custo Aluno-Qualidade exigiria das políticas de financiamento um cálculo mais elaborado sobre as necessidades mínimas das condições de trabalho, de oferta, de desenvolvimento da educação brasileira, em todos os níveis de ensino, garantindo um mínimo de qualidade social para o atendimento da demanda educacional. Tal perspectiva só foi organizada e sintetizada pela moção da sociedade civil organizada, em conferências nacionais de educação e oficinas da Campanha Nacional pelo Direito à Educação.

Como visto, a legislação brasileira prevê a vinculação constitucional de recursos para a educação, porém o que deveria ser o mínimo a ser investido, na prática, torna-se o máximo utilizado para sua manutenção em diversos locais do País, independentemente do ente federado. No geral, o Brasil investe em educação montante muito inferior por aluno do que os países da Organização para Cooperação e Desenvolvimento Econômico (OCDE), conforme podemos ver na figura 2:

Figura 2 - Investimentos do Brasil e Média dos Países da OCDE - 2012

\begin{tabular}{|c|c|c|c|}
\hline \multicolumn{4}{|c|}{ Investimento Financeiro em Educação } \\
\hline & Gasto anual por aluno (valores em USD usando o PPP) & 2012 & 2012 \\
\hline \multirow{3}{*}{ B1.1a } & Anos Iniciais do Ensino Fundamental & 3095 USD & 8247 USD \\
\hline & Anos Finais do Ensino Fundamental e Ensino médio & 3020 USD & 9518 USD \\
\hline & Educação Superior (including R\&D activites) & 10455 USD & 15028 USD \\
\hline
\end{tabular}

Fonte:https://www.oecd.org/brazil/Education-at-a-glance-2015-Brazil-in-Portuguese.pdf

Ou seja, o Brasil gasta muito menos do que os países da OCDE em educação básica, essencial para o desenvolvimento de uma nação. $E$, ainda, a lógica de financiamento vigente no País segue a orientação de distribuir por aluno matriculado os recursos 
disponíveis, cabendo à União, como já visto, a função complementadora de recursos, caso o valor por aluno não atinja o mínimo nacional. Porém, o cálculo usado no Fundeb é realizado sem nenhuma vinculação ao Custo Aluno-Qualidade (CAQ) (DAVIES, 2006). Portanto, não garante o padrão de qualidade que o direito à educação exige para dar acesso e qualidade de ensino a todos os cidadãos brasileiros - exatamente porque a política de financiamento não acompanha a garantia do direito a todos e com qualidade. Neste sentido, afirma Taporosky (2016):

\begin{abstract}
vincular a garantia do direito à educação ao financiamento, assegurando-se padrões mínimos de qualidade, mediante a análise da aplicabilidade da teoria da reserva do possível - que justifica a limitação dos investimentos à disponibilidade orçamentária - sob a ótica do mínimo existencial (p.87)
\end{abstract}

Apesar de a legislação educacional brasileira conter a previsão de estabelecimento de um padrão mínimo de qualidade educacional, como obrigação da União e dos entes federados, foi preciso a sociedade civil organizada realizar o estudo e efetivamente promulgar um padrão mínimo de qualidade (BRASIL, 1996, art. 74).

Portanto, seria obrigação da União e demais entes estabelecer critérios para composição de um padrão mínimo de qualidade do ensino, baseado em um custo mínimo. Tal valor deveria ser corrigido de acordo com as modalidades de ensino. Já o Art. 75 prevê que "A ação supletiva e redistributiva da União e dos estados será exercida de modo a corrigir, progressivamente, as disparidades de acesso a garantir o padrão mínimo de qualidade de ensino". Neste sentido, corrobora-se com a reflexão de Araújo (2016) sobre o comportamento da União, que durante a vigência de aproximadamente dez anos de Fundef, foi diminuindo a participação da União no financiamento da educação, com a postura de não tomar providências para a formatação do padrão mínimo de qualidade, pois

Elaborar os parâmetros do padrão mínimo de qualidade, levando em conta o disposto na LDB, levaria a atrair pra si uma pressão maior por transferência de recursos federais para os demais entes, postura que contrariava a política vigente de enxugamento do Estado (ARAÚJO, 2016, p. 159).

Se o padrão mínimo de qualidade do ensino não era do interesse da União e seus entes federados, foi preciso que a sociedade civil organizada, nas discussões dos fóruns e conferências nacionais de educação, chegasse ao que hoje se chama Custo Aluno-Qualidade (CAQ), que atualmente tem servido de referência para se refletir sobre que qualidade deveria ser ofertada na educação pública brasileira, tentando aproximar o Brasil dos países da OCDE em termos quantitativos e qualitativos de recursos financeiros em educação, conforme afirma Araújo (2016):

A ausência de providências práticas para consubstanciar o padrão mínimo de qualidade por parte do poder público ensejou a formulação de uma proposta alternativa de regulamentação deste dispositivo pela sociedade civil organizada. A Campanha 
Nacional pelo Direito à Educação coordenou um processo de construção participativa do que ficou conhecida como Custo Aluno-Qualidade (CAQ), metodologia desenvolvida como sinônimo de padrão mínimo de qualidade. O resultado deste esforço foi sintetizado por Carreira e Pinto (p. 161).

O estudo reuniu os insumos necessários para se manter uma qualidade no ensino público, não qualquer qualidade ou uma qualidade somente de melhorias de padrões de desempenho, mas uma qualidade social, de melhores condições de processo ensino-aprendizagem, de melhores condições de trabalho e de sucesso dos estudantes da educação básica. Para tanto: “Foi desenvolvida uma matriz que buscou relacionar a qualidade oferecida em cada uma das etapas e modalidades do ensino com os insumos necessários" (ARAÚJO, 2016, p. 161).

Os insumos foram definidos nas seguintes categorias: estrutura e funcionamento, trabalhadoras e trabalhadores em educação, gestão democrática e acesso e permanência na escola, sendo calculados para cada etapa (educação infantil, ensino fundamental e ensino médio) e modalidade (EJA, educação especial, educação indígena, educação a distância, educação profissional e educação do campo) e considerando os grandes desafios de diferenças regionais, econômicas, raciais, de gênero etc.

Quanto aos insumos, destaca-se o que os autores consideraram a definição das quatro categorias: condições de estrutura e funcionamento, valorização das/dos profissionais, gestão democrática e acesso e permanência.

Sobre a estrutura e o funcionamento, os autores viram a necessidade de um padrão de prédios como locais agradáveis tanto para quem ensina quanto para quem aprende, espaços convidativos para a permanência e para o desenvolvimento das atividades didático-pedagógicas. É fundamental, por exemplo, que os professores tenham um local de trabalho e de convivência. A presença da natureza (árvores, flores, grama, horta etc.) também é uma preocupação primordial, superando o modelo de "cimento total" (CARREIRA e PINTO, 2007, p.29).

Sobre os insumos relacionados aos trabalhadores e trabalhadoras em educação, os autores identificaram nas oficinas realizadas para síntese dos estudos muitos problemas comuns a muitas escolas quanto à fragmentação das políticas de formação, o não reconhecimento de trabalhadores e trabalhadoras em educação, além dos profissionais do magistério, não serem considerados como membros da educação - por exemplo, vigias, merendeiras, serventes etc. e, ainda, a falta de carreira docente e o número excessivo de alunos por turma.

Nota-se que o estudo abrange aspectos que, mesmo após dez anos de registro, ainda estão presentes na atuação docente nas escolas públicas brasileiras, por exemplo, o piso nacional, agora estabelecido na Lei n. 11.738 de 2008, que ainda não é pago em todas as regiões do Brasil, a jornada de trabalho que ainda não vigora em grande parte das escolas públicas brasileiras, obrigando muitos professores a dar aula em várias escolas para 
fechar sua carga horária, e o quantitativo de alunos por turma, que ainda não é considerado de acordo com as possibilidades do professor, para manter a qualidade do ensino, a necessidade das secretarias de ensino em matricular alunos próximos as suas residências, diante das poucas vagas disponíveis, que ainda autoriza o excesso de alunos por sala. São problemas que ainda persistem e que merecem ser vistos de forma cuidadosa quando se quer calcular a qualidade do ensino.

Quanto à gestão democrática, os autores chamam atenção para a necessidade de participação dos membros das comunidades educativas nas decisões das escolas públicas. Também se ressalta a gestão democrática como um sonho presente e desafiador, pois o fato é que, em pleno século XXI, nossas escolas ainda não têm a cultura democrática como prática viva em sua rotina escolar.

Por fim, os autores destacaram aspectos necessários para o acesso e permanência com vistas a criar condições para garantir o acesso e a permanência dos estudantes na escola. Ressaltam ainda uma atenção especial para

\begin{abstract}
a chamada escolar, ou "minicenso", e o censo anual da população na faixa de escolaridade obrigatória são instrumentos fundamentais para assegurar o acesso e a permanência, já que permitem identificar e localizar as crianças que estão fora da escola. As condições para a concretização do período integral também devem ser garantidas por uma política de financiamento que fomente a jornada única do professorado (CARREIRA e PINTO, 2007, p. 32, grifo nosso).
\end{abstract}

Contudo, nenhuma escola brasileira é igual à outra; neste sentido, seria necessário avançar para uma forma de garantir a educação como direito social com um mínimo de qualidade. Surge então o CAQi, “como uma resposta a esse inviolável direito, ou seja, o de garantir que cada cidadão desse país tenha acesso a uma educação de qualidade, ao apresentar com clareza os insumos necessários a esse direito" (BRASIL, 2010, p. 4).

Para Rezende Pinto (2003), o CAQi representa um ponto de partida, uma proposta inicial e de transição para o investimento em educação de qualidade, ao considerar os insumos básicos que todas as escolas deveriam assegurar minimamente, tais como o tamanho das escolas e suas instalações, a oferta de recursos didáticos em quantidade e qualidade, a razão alunos/turma, a remuneração, formação e jornada do pessoal, a jornada dos alunos, os projetos especiais e a gestão democrática.

Tanto quanto o CAQ, o CAQi pauta-se nos custos de manutenção e atualização das escolas e não da construção de novas unidades (PINTO, 2003), pois pensa exatamente nas escolas brasileiras já existentes, da forma como elas estão, com suas características próprias de quantitativo de pessoal, alunos atendidos e infraestrutura real. A ideia é pensar em quanto se gastaria para manter com qualidade essa escola, mas deixando claro que no CAQi, os custos de maior impacto, assim como no financiamento da educação, são os relativos ao pessoal (PINTO, 2003). 
Os estudos do CAQ e do CAQi também fazem diferença para a oferta em tempo integral e tempo parcial, em cada etapa de ensino, o que pode ser considerado um avanço para a implementação das políticas de educação de tempo integral. A seguir se faz referência à etapa de maior interesse deste estudo, o ensino médio e sua oferta em tempo integral. O que é, quanto custa essa oferta com qualidade em tempo integral?

\section{O CAQi e os desafios à qualidade do ensino médio}

Falar em garantia do direito à educação, com qualidade social, é realmente um desafio grande no cenário brasileiro, especialmente no ensino médio, diante do que revelam os dados da realidade nacional nesta etapa. Com base nestes desafios, a Campanha Nacional pelo Direito à Educação, de acordo com os estudos de Carreira e Pinto (2007), organizaram uma base de cálculo do CAQi, a fim de registrar o quanto uma escola de ensino médio com os requisitos mínimos de um padrão de qualidade custaria para o Estado e, se fosse em tempo integral, o quanto esse custo aumenta.

Segundo Carreira e Pinto (2007), o CAQi do ensino médio foi calculado tendo por base uma escola com

900 alunos distribuídos em 30 turmas (15 salas), com média de 30 alunos por turma, em dois turnos, com jornada de 25 horas por semana para os alunos. Essa escola teria trinta professores em jornada integral de 40 horas semanais (32 delas com os alunos), dois diretores, dois coordenadores pedagógicos, dois bibliotecários, quatro secretários, oito funcionários para manutenção e conservação (quatro deles com formação no ensino fundamental e quatro no ensino médio) e quatro funcionários no setor de alimentação (p. 104).

Os autores também definiram o que comportaria os custos da implantação do ensino médio, apresentando características gerais de uma escola que contaria mais ou menos com esta infraestrutura:

prédio com 15 salas de aula, laboratórios de química, física, biologia e informática e uma quadra coberta de 500 metros quadrados, ao custo total estimado de 1,1 milhão de reais. Em equipamentos e material permanente, os custos atingiram a cifra estimada de 476 mil reais (p. 104).

Destaca-se, ainda, para este estudo, os custos sintetizados pelos autores para a implantação do ensino médio em tempo integral, considerando o quantitativo de alunos, a jornada mínima de 7 horas diárias e uma média de 30 alunos por turma. Apresentamos, assim, os valores para o ensino médio em tempo integral, no ano de 2018, conforme a tabela 1. 
Tabela 1 - Custo aluno ensino médio (CAQI) 2018

\begin{tabular}{l|c|c|c|c}
\hline Etapa de ensino & $\begin{array}{c}\text { Carga } \\
\text { horária }\end{array}$ & $\begin{array}{c}\text { Alunos por } \\
\text { sala }\end{array}$ & Custo/valor & Propostas \\
\hline Ensino Médio (tempo integral) & $35 \mathrm{~h}$ & 35 & $\mathrm{R} \$ 8.293,19$ & $\mathrm{CAQi}$ \\
\hline
\end{tabular}

Fonte: caq.org.br

Apresentamos ainda a tabela 2 com os valores do Fundeb para os estados brasileiros a vigorar em 2019.

Tabela 2 - Anexo I da portaria interministerial no 7/2018

\begin{tabular}{|c|c|c|c|c|}
\hline \multicolumn{5}{|c|}{ Ensino Médio } \\
\hline Estados & Urbano & Rural & Tempo Integral & Int. Ed. Profissional \\
\hline $\mathrm{AC}$ & $4.435,09$ & $4.612,50$ & $4.612,50$ & $4.612,50$ \\
\hline $\mathrm{AL}$ & $4.048,15$ & $4.210,08$ & $4.210,08$ & $4.210,08$ \\
\hline $\mathrm{AM}$ & $4.048,15$ & $4.210,08$ & $4.210,08$ & $4.210,08$ \\
\hline $\mathrm{AP}$ & $5.212,40$ & $5.420,90$ & $5.420,90$ & $5.420,90$ \\
\hline BA & $4.048,15$ & $4.210,08$ & $4.210,08$ & $4.210,08$ \\
\hline $\mathrm{CE}$ & $4.048,15$ & $4.210,08$ & $4.210,08$ & $4.210,08$ \\
\hline DF & $4.976,34$ & $5.175,39$ & $5.175,39$ & $5.175,39$ \\
\hline ES & $4.324,42$ & $4.497,40$ & $4.497,40$ & $4.497,40$ \\
\hline GO & $4.546,97$ & $4.728,84$ & $4.728,84$ & $4.728,84$ \\
\hline MA & $4.048,15$ & $4.210,08$ & $4.210,08$ & $4.210,08$ \\
\hline MG & $4.274,21$ & $4.445,18$ & $4.445,18$ & $4.445,18$ \\
\hline MS & $4.633,28$ & $4.818,61$ & $4.818,61$ & $4.818,61$ \\
\hline MT & $4.494,11$ & $4.673,87$ & $4.673,87$ & $4.673,87$ \\
\hline PA & $4.048,15$ & $4.210,08$ & $4.210,08$ & $4.210,08$ \\
\hline PB & $4.048,15$ & $4.210,08$ & $4.210,08$ & $4.210,08$ \\
\hline PE & $4.048,15$ & $4.210,08$ & $4.210,08$ & $4.210,08$ \\
\hline PI & $4.579,49$ & $4.762,67$ & $4.762,67$ & $4.762,67$ \\
\hline PR & $4.512,95$ & $4.693,47$ & $4.693,47$ & $4.693,47$ \\
\hline RJ & 4.338 .54 & $4.512,08$ & $4.512,08$ & $4.512,08$ \\
\hline RN & $4.313,45$ & $4.485,99$ & $4.485,99$ & $4.485,99$ \\
\hline $\mathrm{RO}$ & $4.462,34$ & $4.828,03$ & $4.828,03$ & $4.828,03$ \\
\hline
\end{tabular}




\section{Ensino Médio}

\begin{tabular}{c|c|c|c|c}
\hline Estados & Urbano & Rural & Tempo Integral & Int. Ed. Profissional \\
\hline RR & $6.111,22$ & $6.355,67$ & $6.355,67$ & $6.355,67$ \\
\hline RS & $5.344,28$ & $5.558,05$ & $5.558,05$ & $5.558,05$ \\
SC & $4.766,39$ & $4.957,04$ & $4.957,04$ & $4.957,04$ \\
\hline SE & $4.797,91$ & $4.989,83$ & $4.989,83$ & $4.989,83$ \\
SP & $4.886,39$ & $5.081,85$ & $5.081,85$ & $5.081,85$ \\
\hline TO & $5.208,85$ & $5.417,21$ & $5.417,21$ & $5.417,21$ \\
\hline
\end{tabular}

Fonte: Portaria Interministerial $n^{\circ} 7 / 2018$.

A partir dos dados apresentados, percebe-se que o valor aluno-ano para a etapa de ensino médio em tempo integral, atribuído na portaria do Fundeb, em 2018, chega no máximo a $\mathrm{R} \$$ 6.355,67 para o estado de Roraima, enquanto a proposta do CAQi para esta mesma etapa e modalidade de oferta fica em $\mathrm{R} \$ 8.293,19$, para se iniciar a oferta com qualidade, garantindo os insumos necessários para a efetiva qualidade no ensino médio em tempo integral.

Nota-se que os custos de uma educação de qualidade estão tão distantes da realidade brasileira e significam substantiva mudança de postura do Governo para sua implementação. Alguns documentos oficiais já reconhecem a importância e propõem ações para adoção do CAQi e, posteriormente, do CAQ, como base para o cálculo do valor aluno-ano.

No atual PNE, aprovado em 2014, a proposta do CAQi para a educação básica foi considerada na Meta 20, que trata da ampliação do recurso financeiro público na educação pública para atingir, no mínimo, 7\% (sete por cento) do Produto Interno Bruto (PIB) do País no 5ํo ano de vigência e, no mínimo, o equivalente a $10 \%$ do PIB ao final do decênio. Em suas estratégias, a Meta 20 compreende:

20.6) no prazo de 2 (dois) anos da vigência deste PNE, será implantado o Custo Aluno-Qualidade inicial - CAQi, referenciado no conjunto de padrões mínimos estabelecidos na legislação educacional e cujo financiamento será calculado com base nos respectivos insumos indispensáveis ao processo de ensino-aprendizagem e será progressivamente reajustado até a implementação plena do Custo Aluno Qualidade-CAQ;

20.7) implementar o Custo Aluno Qualidade - CAQ como parâmetro para o financiamento da educação de todas etapas e modalidades da educação básica, a partir do cálculo e do acompanhamento regular dos indicadores de gastos educacionais com investimentos em qualificação e remuneração do pessoal docente e dos demais profissionais da educação pública, em aquisição, manutenção, construção e conservação de instalações e equipamentos necessários ao ensino e em aquisição de material didático-escolar, alimentação e transporte escolar;

20.8) o CAQ será definido no prazo de 3 (três) anos e será continuamente ajustado, com base em metodologia formulada pelo Ministério da Educação - MEC, e 
acompanhado pelo Fórum Nacional de Educação - FNE, pelo Conselho Nacional de Educação - CNE e pelas Comissões de Educação da Câmara dos Deputados e de Educação, Cultura e Esportes do Senado Federal (BRASIL, 2014)

Observa-se que nas estratégias 6, 7 e 8, da Meta 20 do PNE, a implantação do CAQi e, posteriormente, do CAQ fazem parte do texto legal e tem prazo definido para ser efetivada na política educacional brasileira. No entanto, vale assinalar que o prazo de dois anos para oCAQi já se esgotou em 2016 e os ajustes ainda não foram realizados até 2019.

Sobre a ampliação do ensino médio em tempo integral, podemos observar que o PNE 2014 prevê na Meta 6: “Oferecer educação em tempo integral em, no mínimo, 50\% (cinquenta por cento) das escolas públicas, de forma a atender, pelo menos, $25 \%$ (vinte e cinco por cento) dos (as) alunos (as) da educação básica", tendo como estratégias:

\begin{abstract}
6.1) promover, com o apoio da União, a oferta de educação básica pública em tempo integral, por meio de atividades de acompanhamento pedagógico e multidisciplinares, inclusive culturais e esportivas, de forma que o tempo de permanência dos (as) alunos (as) na escola, ou sob sua responsabilidade, passe a ser igual ou superior a 7 (sete) horas diárias durante todo o ano letivo, com a ampliação progressiva da jornada de professores em uma única escola;

6.2) instituir, em regime de colaboração, programa de construção de escolas com padrão arquitetônico e de mobiliário adequado para atendimento em tempo integral, prioritariamente em comunidades pobres ou com crianças em situação de vulnerabilidade social;

6.3) institucionalizar e manter, em regime de colaboração, programa nacional de ampliação e reestruturação das escolas públicas, por meio da instalação de quadras poliesportivas, laboratórios, inclusive de informática, espaços para atividades culturais, bibliotecas, auditórios, cozinhas, refeitórios, banheiros e outros equipamentos, bem como da produção de material didático e da formação de recursos humanos para a educação em tempo integral.
\end{abstract}

Observamos que nas primeiras estratégias da Meta 6 do PNE, a construção, revitalização de escolas, bem como a instalação de espaços diferenciados são necessários para a dinamização do que o PNE prevê como tempo integral para a educação básica. No que diz respeito ao ensino médio, a necessidade de equipamentos de informática, bibliotecas, auditórios, laboratórios de ciências, se faz necessário para a ampliação do acesso desta etapa com qualidade, daí a importância de se mudar a lógica do financiamento da educação brasileira da perspectiva de "gasto" para a perspectiva do "custo", na tentativa de se chegar a um mínimo necessário para uma oferta de qualidade. 


\section{Considerações finais}

Apesar de a legislação brasileira ter vinculado recursos para a educação ser ofertada com um padrão mínimo de qualidade, a garantia da lei não traduz sua efetividade. Os entes federados responsáveis pelo estabelecimento do que seria o padrão mínimo de qualidade não o fizeram, estabelecendo ao longo da política de fundos (Fundef e Fundeb) um valor mínimo por aluno-ano, de acordo com os recursos disponíveis para o gasto com a educação.

A partir do Fundeb, o ensino médio passa a ser comtemplado como etapa de ensino integrante do recebimento de recursos vinculados, com a diferenciação das ponderações para sua oferta no meio urbano, rural, em tempo integral e integrado à educação profissional, porém, sem a devida descrição dos insumos necessários para uma oferta de qualidade desta etapa em suas diferentes formas de atendimento.

De maneira geral, a política implementada de gasto com a educação tem sido praticada no sentido de redistribuir os recursos mínimos disponíveis pelo número de alunos matriculados. Portanto, não se parte dos alunos matriculados, das necessárias condições estruturais, de trabalho, de manutenção desses alunos para se orçar o quanto é preciso para oferecer uma educação de qualidade. Muito menos se planeja os gastos futuros pensando, efetivamente, numa projeção de custos para a garantia da educação com qualidade.

Tendo os parâmetros do CAQi para o ensino médio e(m) tempo integral, apresentados no estudo, nota-se que ainda há muito a se considerar para a oferta de um ensino médio de qualidade em tempo integral. Embora legalmente as metas 6 e 20 do PNE 2014 nos indiquem a necessidade e o compromisso brasileiro, tanto na ampliação do tempo integral na educação básica quanto na mudança da lógica do financiamento educacional do "gasto" para o "custo", ainda há muito que avançar para a efetiva mudança na lógica de financiamento da educação.

Recebido em: 21/09/2019 e Aprovado em: 06/10/2019

\section{Notas}

1 Para maiores informações sobre o histórico do financiamento educacional no Brasil, ver Monlevade (1997). 


\section{Referências}

ARAÚJO, Luiz. O CAQi e o novo papel da União no financiamento da Educação Básica. Jundiaí: Paco Editorial, 2016.

BRASIL. Casa Civil Federal. Lei no 13.005: Plano Nacional de Educação. Brasília: 2014.

. Emenda Constitucional nº 93, de 08 de setembro de 2016. (Altera o Ato das Disposições Constitucionais Transitórias para prorrogar a desvinculação de receitas da União e estabelecer a desvinculação de receitas dos Estados, Distrito Federal e Municípios). Disponível em: <http://www. planalto.gov.br/ccivil_03/constituicao/emendas/emc/emc93.htm>. Acesso em:1 mar. 2018.

1996.. Senado Federal. Lei de Diretrizes e Bases da Educação Nacional: no 9394/96. Brasília: MEC,

CARREIRA, Denise; PINTO, José Marcelino. Custo aluno-qualidade inicial: rumo à educação pública de qualidade no Brasil. São Paulo: Global, 2007, p. 80.

CARVALHO, Fabrício Aarão Freire. Financiamento da Educação: do FUNDEF ao FUNDEB -

Repercussões da política de fundos na valorização docente da rede estadual do Pará - 1996 a 2009.2012. Tese de Doutorado em Educação - USP, São Paulo, 2012.

FAJARDO, V. 53\% dos Jovens Brasileiro estão no Ensino Médio, média da OCDE É DE 95\% - Dados integra a mais recente edição do estudo "Educationat a Glance" ("Um olhar sobre a educação", na tradução livre do Inglês).Disponível em: <https://g1.globo.com/educacao/noticia/53-dos-jovensbrasileiros-estao-no-ensino-medio-media-da-ocde-e-de-95.ghtml>. Acesso em: 22 dez.2017.

GOUVEIA, Andrea Barbosa.; SOUSA, Ângelo Ricardo de. Política de fundos em perspectiva histórica: mudanças de concepção da política na transição Fundef e Fundeb. Em Aberto, Brasília, v. 28, n. 93, p. 45-65, 2015.

GUIMARÃES, José Luiz. Do FUNDEF ao FUNDEB: uma breve reflexão sobre as recentes mudanças no financiamento da educação brasileira. Revista Política Educacional,2010. Disponível em: <https:// acervodigital.unesp.br/handle/123456789/35>. Acesso em: 20 fev. 2018.

INEP. IDEB - Resultados e Metas. Disponível em: <http://ideb.inep.gov.br/>. Acesso em: 31 dez. 2017.

MADZA, Ednir; BASSI, Marcos. Bicho de sete cabeças: para entender o financiamento da educação brasileira. São Paulo: Ação Educativa, 2009.

MENEZES, Janaina. Educação integral e tempo integral na educação básica: da LDB ao PDE. Rio de Janeiro, 2007. Disponível em: <http://portal.virtual.ufpb.br/biblioteca virtual/files/pub_1291081139.pdf> Acessado em: 7dez. 2015. 152, 2012.

Educação em tempo integral: Direito e financiamento. Educar em Revista, Curitiba, n. 45, p. 137-

MONLEVADE, João. Educação Pública no Brasil: contos e descontos. Brasília: Editora Ideia. 1997.

PORTALCAQ\&CAQ. Site Oficial. Disponível em: <http://www.custoalunoqualidade.org.br/>. Acesso em: 2 jan. 2018.

RAMOS, Angélica Maria Pinheiro. O financiamento da educação brasileira no contexto das mudanças político-econômicas pós-90. Brasília: Plano Editora, 2003. 
ROCHA, D.C.C.; MONLEVADE, João Cabral.; AGUIAR, R.R. Financiamento e gestão orçamentária da educação. Brasília: Ministério da Educação, 2006.

ROSSINHOLI, Marisa. Política de Financiamento da Educação Básica no Brasil: do FUNDEB ao FUNDEF. Brasília: Liber livro, 2010.

SAVIANI, Dermeval. Da nova LDB ao FUNDEB: por uma outra política educacional. 2. ed. Campinas: Autores Associados, 2008. (Col.Educação Contemporânea).

TAPOROSKY, Barbara Cristina Hanauer. O valor anual mínimo por aluno do FUNDEB, o CAQi e a reserva do possível. Fineduca, v. 6, 2016. Disponível em: $<$ http://www.fnde.gov.br/financiamento/ fundeb/fundeb-consultas>

http://campanhaeducacao.org.br

http://www.custoalunoqualidade.org.br/calculos-do-caqi-e-do-caq

http://portal.mec.gov.br/politica-de-educacao-inclusiva/128-perguntas-frequentes-911936531/fundeb1960787641/142-de-onde-vem-os-recursos-do-fundeb. 